\title{
Stent-graft balloon occlusion with selective cerebral perfusion for cardiac surgery after proximal aortic arch stent grafting: A case report
}

Takayuki Shijo, MD, Akira Marumoto, MD, PhD, and Keiji Iwata, MD, PhD, Osaka, Japan

From the Department of Cardiovascular Surgery, JCHO Osaka Hospital, Osaka, Japan.

Disclosures: Authors have nothing to disclose with regard to commercial support.

Received for publication April 8, 2017; revisions received June 5, 2017; accepted for publication July 3, 2017; available ahead of print Aug 29, 2017.

Address for reprints: Takayuki Shijo, MD, Department of Cardiovascular Surgery, JCHO Osaka Hospital, 4-2-78, Fukushima, Fukushima-ku Osaka-shi, Osaka 553-0003, Japan (E-mail: shijo0903@ hotmail.co.jp).

J Thorac Cardiovasc Surg 2018;155:520-2

$0022-5223 / \$ 36.00$

Copyright $(2017$ by The American Association for Thoracic Surgery

http://dx.doi.org/10.1016/j.jtcvs.2017.07.046

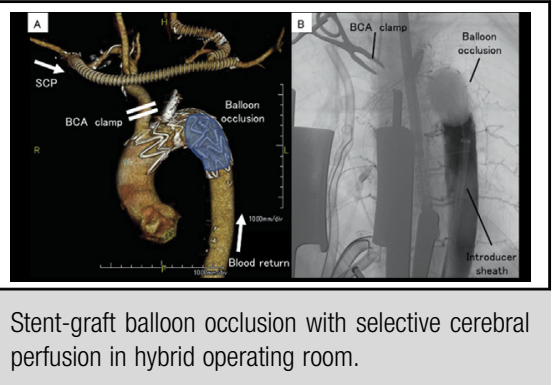

Video clip is available online.

\section{Central Message}

The stent-graft balloon occlusion technique with selective cerebral perfusion in a hybrid operating room could be an option for cardiac surgery after hybrid aortic arch repair.

See Editorial Commentary page 523.
In recent years, stent grafting of the aortic arch and ascending aorta has become a reality; however, endovascular treatment of the ascending aorta poses a challenge for further cardiac surgery with regard to the requirement of aortic crossclamping. ${ }^{1,2}$ Aortic crossclamping of a stented ascending aorta could deform the stent graft and cause severe complications, such as iatrogenic aortic dissection, aortic perforation, and endoleak. On the other hand, endoaortic balloon occlusion has been well established, and it enables aortic clamp-free cardiac surgery. ${ }^{3,4}$ In detail, a balloon catheter is delivered to the ascending aorta by the transfemoral approach under transesophageal echocardiographic guidance. The balloon is inflated at just above the sinotubular junction, the size of which is judged from preoperative computed tomography. Here we present a case of cardiac surgery after proximal aortic arch stent grafting with a stent-graft balloon occlusion technique with selective cerebral perfusion (SCP) in a hybrid operating room.

\section{CLINICAL SUMMARY}

A 78-year-old man had shortness of breath develop, and an echocardiogram revealed severe mitral valve regurgitation. The patient had undergone aortic arch repair for a saccular aneurysm about 1 year previously, at which time mitral valve regurgitation had not been detected. He was of advanced age and had some comorbidities. After explanation of the treatment options, the patient elected to undergo hybrid repair. With regard to the initial surgery, the left subclavian artery and left carotid artery were bypassed from the right subclavian artery with an 8-mm expanded polytetrafluoroethylene graft, and a stent graft (Relay Plus; Bolton Medical, Sunrise, Fla) was deployed into the landing zone 1 (Figure 1, A). Although the covered part of the stent graft was placed just below the brachiocephalic artery, the proximal bare stent extended to the middle portion of the ascending aortic lesser curvature (Figure 1, B).

Mitral valve repair was performed in a hybrid operating room. An arterial cannula was inserted into the left femoral artery and the right axillary artery, and venous drainage was achieved with bicaval cannulation. After establishment of cardiopulmonary bypass, the brachiocephalic artery was clamped, and SCP was started through the right axillary artery by way of the previous rerouting bypass (Figure 2, A).

Under fluoroscopic guidance, a 5F Headhunter catheter (Terumo, Tokyo, Japan) and 0.035-inch Radifocus guidewire (Terumo) were advanced into the ascending aorta through the right femoral artery. The guidewire was exchanged for a super-stiff Amplatz wire (Boston Scientific, Marlborough, Mass), and a 16F Check-Flo introducer sheath (Cook Medical, Bloomington, Ind) was advanced up to the distal end of the stent graft. A TMP Lock balloon catheter (Tokai Medical Products, Aichi, Japan) was delivered into the stent graft and was then inflated for occlusion (Figure 2, A). Complete occlusion was confirmed by angiography through the introducer sheath (Figure 2, $B$, and Video 1). Cardioplegic solution was administered into the 


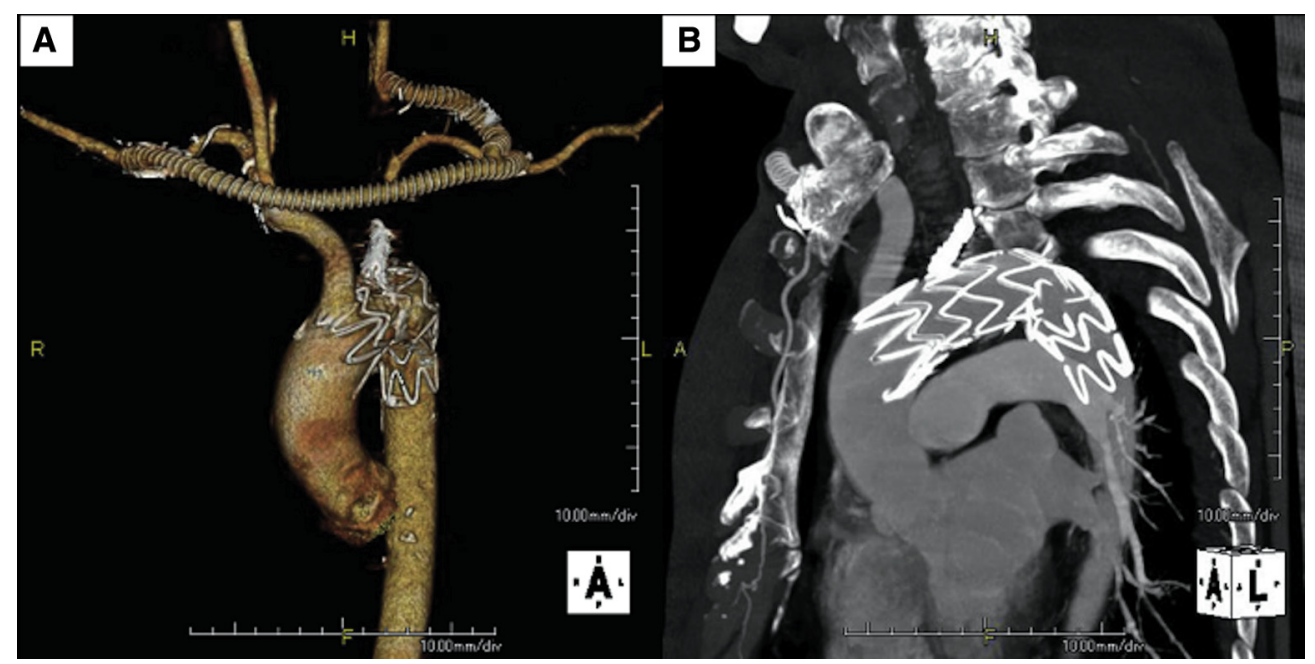

FIGURE 1. Computed tomography after hybrid aortic arch repair. A, The left subclavian artery and left carotid artery are subcutaneously bypassed from the right subclavian artery. B, The covered part of the stent graft is placed just below the brachiocephalic artery. The proximal bare stent is extended to the middle portion of the ascending aortic lesser curvature.

aortic root, and cardiac arrest was promptly obtained. Mitral valve repair was performed uneventfully. The occlusion balloon was deflated after left ventricular deairing. After confirmation of residual air absence in the aortic root by transesophageal echocardiography, SCP was terminated by declamping the brachiocephalic artery, and the patient was weaned from cardiopulmonary bypass. The patient had neither neurologic deficit nor aortic complications. He has been followed up as an outpatient without any symptoms for 3 months.

\section{DISCUSSION}

After zone 0 or zone 1 stent grafting with a proximal bare stent, the tip of the device is extended to the ascending aorta. ${ }^{1,2}$ In our case, we were concerned that ascending aorta crossclamping could deform the stent graft and cause aortic injury associated with the proximal bare stent.

The clampless technique involving ascending aortic occlusion with an endoaortic balloon has been well established for minimally invasive cardiac surgery. The conventional endoaortic balloon occlusion technique, however, carries a risk of iatrogenic aortic dissection and stroke when used for an improper aorta. In addition, endoaortic balloon occlusion has a learning curve, probably because manipulation is guided by transesophageal echocardiography alone. ${ }^{3,4}$

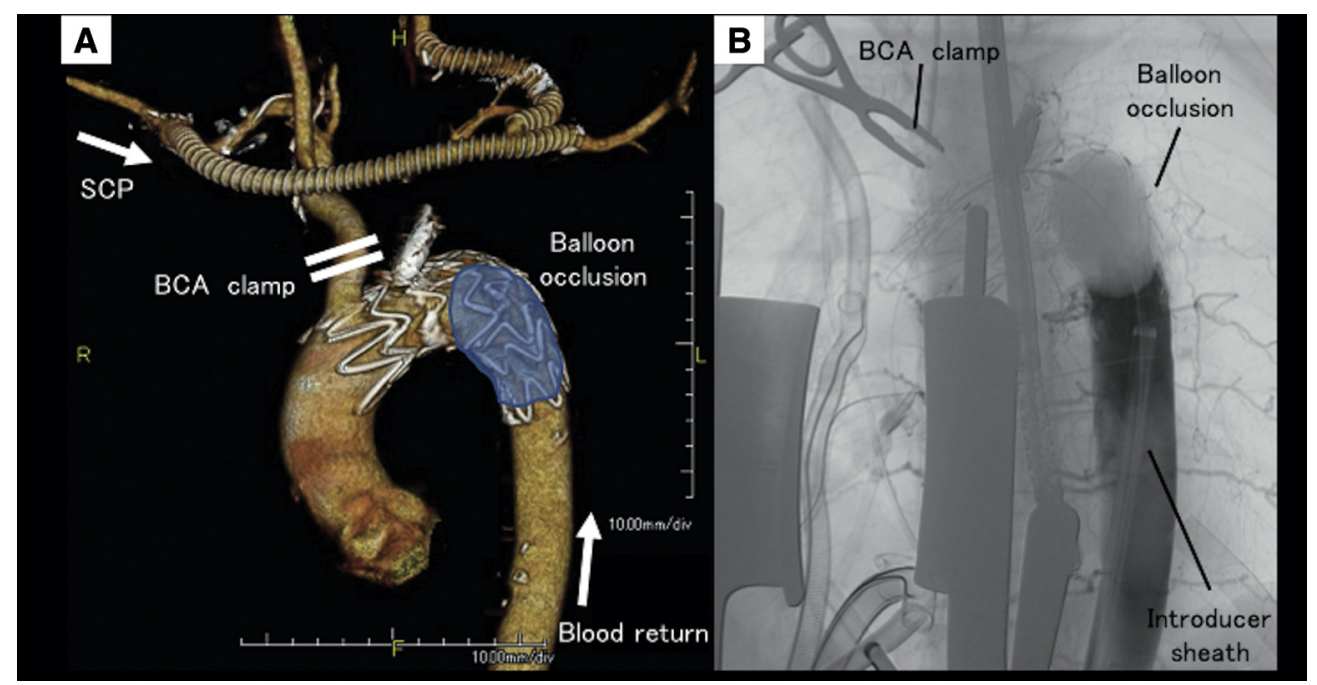

FIGURE 2. Stent-graft balloon occlusion with selective cerebral perfusion. A, A TMP Lock balloon catheter (Tokai Medical Products, Aichi, Japan) is delivered into the stent graft and is inflated to occlude the descending aorta. B, Complete aortic occlusion is confirmed by angiography through the introducer sheath. $S C P$, Selective cerebral perfusion; $B C A$, brachiocephalic artery. 


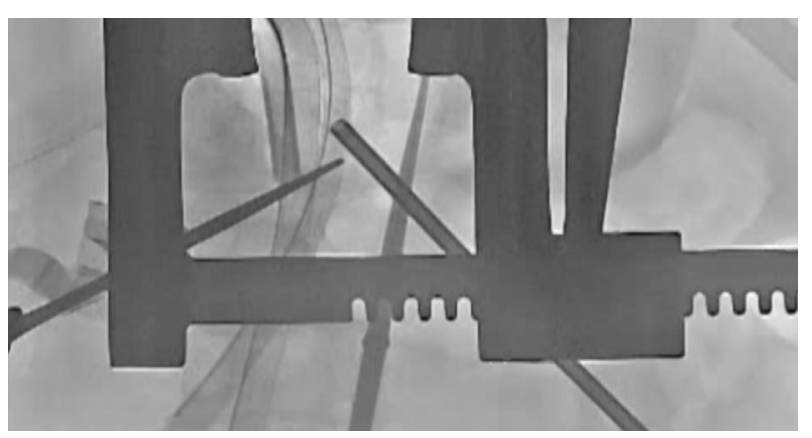

VIDEO 1. Stent-graft balloon occlusion. A $16 \mathrm{~F}$ Check-Flo introducer sheath (Cook Medical, Bloomington, Ind) is advanced up to the distal end of the stent graft. A TMP Lock balloon catheter (Tokai Medical Products, Aichi, Japan) is delivered into the stent graft and is inflated for occlusion. Complete occlusion is confirmed by angiography through the introducer sheath. Video available at: http://www.jtcvsonline.org/article/ S0022-5223(17)31591-X/fulltext.

Stent-graft balloon occlusion with SCP under fluoroscopic guidance is considered to decrease the risk of aortic injury and balloon dislocation. We can clearly detect the previously inserted stent graft under fluoroscopy, and the balloon can be inflated at the middle portion of the stent graft without reaching the edge. In this case, we used a long introducer sheath to stabilize the endoaortic balloon and confirmed complete aortic occlusion.

When planning ascending aortic stent grafting, potential cardiac diseases should be carefully examined for; if any are noted, hybrid arch repair should be avoided. When there is a need for cardiac surgery after ascending aortic stent grafting, however, stent-graft occlusion and SCP could be considered possible options. Further evaluation and modification of our technique are warranted.

\section{References}

1. Vallabhajosyula P, Szeto W, Desai N, Bavaria JE. Type I and type II hybrid aortic arch replacement: postoperative and mid-term outcome analysis. Ann Cardiothorac Surg. 2013;2:280-7.

2. Shirakawa Y, Kuratani T, Shimamura K, Torikai K, Sakamoto T, Shijo T, et al. The efficacy and short-term results of hybrid thoracic endovascular repair into the ascending aorta for aortic arch pathologies. Eur J Cardiothorac Surg. 2014;45: 298-304; discussion 304.

3. Zingone B, Gatti G, Rauber E, Pappalardo A, Benussi B, Dreas L. Surgical management of the atherosclerotic ascending aorta: is endoaortic balloon occlusion safe? Ann Thorac Surg. 2006;82:1709-14.

4. Kowalewski M, Malvindi PG, Suwalski P, Raffa GM, Pawliszak W, Perlinski D, et al. Clinical safety and effectiveness of endoaortic as compared to transthoracic clamp for small thoracotomy mitral valve surgery: meta-analysis of observational studies. Ann Thorac Surg. 2017;103:676-86.

5. Shijo T, Kuratani T, Torikai K, Shimamura K, Sakamoto T, Kudo T, et al. Thoracic endovascular aortic repair for degenerative distal arch aneurysm can be used as a standard procedure in high-risk patients. Eur J Cardiothorac Surg. 2016;50: $257-63$. 